Autor: Bryan González

Hernández

Bryan González Hernández (Costa Rica,

1984). Doctor en Estudios Latinoamericanos con énfasis en Pensamiento

Latinoamericano. Maestría en Estudios

Latinoamericanos con énfasis en Cultura

y Desarrollo. Licenciatura en Relaciones

Internacionales con énfasis en Política

Internacional. Actualmente es Director de la

Escuela de la Tierra, Longo Maï, Costa Rica.

Lineas de investigación: Necrogeopolitica y

biogeopolítica de la guerra total; Seguridad

y producción espacial de la seguridad;

Colapso mundial; Teorías y modelos de

desarrollo; Derecho y estado de excepción;

Anarquismo y teorías críticas; Diseño de

permacultura.

Correo electrónico: antogonza@gmail.com https://orcid.org/0000-0003-1497-1310

\section{ARGOS PANOPTES. \\ O LA MATERIA, \\ FORMA Y PODER DEL ESTADO EN EL CONTEXTO DEL COLAPSO MUNDIAL}

(Argos Panoptes. Or the matter, form and power of the state in the context of world collapse)

Ruge ese monstruo: No hay nada en la tierra que esté por encima de mí; yo soy el dedo imperativo de

dios.

Friedrich Nietzsche

Dios nos odia.

Santiago López Petit

No le deseo un Estado a nadie.

Espai en blanc 
Resumen: El objetivo central de este artículo consiste en analizar el modelo de Estado para el siglo XXI cuya consolidación se acelera con los acontecimientos del 11 de setiembre de 2001 en los Estados Unidos. Se considera a este modelo de Estado securitario como una máquina de gestión inmunitaria para un contexto de colapso mundial caracterizado por una serie de destrucciones planetarias y de aniquilación biológica. Es un Estado que radicaliza la conjunción de los poderes militares con los policiales con el propósito de pacificar a sus poblaciones mediante la vigilancia total y la amenaza de guerra contra quienes considera sus enemigos, valiéndose de todos los medios e instrumentos que dispone para cumplir con sus objetivos.

El artículo es de tipo teórico-documental, por lo que centra su interés en la revisión de fuentes bibliográficas documentos oficiales, textos académicos y otras, todo ello interconectado y analizado para dar sentido a la línea argumentativa y el desarrollo teórico de lo que se considera como el modelo de Estado para el siglo XXI.

Palabras claves: Estado total; Vigilancia; Colapso Mundial; Derecho penal del enemigo; Pacificación de las poblaciones.

\begin{abstract}
The main objective of this article is to analyze the State model for the 21st century whose consolidation accelerates with the events of September 11, 2001 in the United States. This model of the security state is considered as an immune management machine in a context of global collapse characterized by a series of planetary destructions and biological annihilation. It is a State that radicalizes the conjunction of the military powers with the police with the purpose of pacifying its populations through total surveillance and the threat of war against those it considers to be its enemies, using all the means and instruments it has at its disposal to fulfill its objectives.

The article is of a theoretical-documentary type, so it focuses on the review of bibliographic sources, official documents, academic texts and others, all interconnected and analyzed to make sense of the argumentative line and the theoretical development of what is considered as the state model for the 21st century.
\end{abstract}

Keywords: Total State; Surveillance; World Collapse; Criminal law of the enemy; Pacification of populations.

\title{
Introducción
}

$H$ I presente artículo es parte de los resultados de una investigación doctoral que estudia el proyecto imperial de los Estados Unidos para el siglo XXI y su vínculo con la producción espacial de la seguridad llevada a cabo bajo excusa de la guerra contra las drogas en la región mesoamericana. De ahí se desprende el análisis de un modelo de estado de seguridad que pretende la vigilancia total y la pacificación de las poblaciones para hacer frente a las catástrofes y el acelerado agotamiento de los recursos considerados como estratégicos, que caracterizan al actual contexto de colapso mundial.

El abordaje metodológico que se empleó para realizar esta investigación partió de una epistemología anarquista que considera como fundamental el principio todo vale para estudiar el contexto actual de colapso mundial, en cuanto que "debería esperarse que los cambios catastróficos del medio ambiente físico, las guerras, el colapso de los sistemas de moralidad imperantes o las revoluciones políticas transformen los modelos de reacción de los adultos, incluidos importantes modelos de argumentación" (Feyerabend, 2002: 19-20).

Este "todo vale" es el que permite el ejercicio de una "filosofía de la situación", que busca analizar la situación actual desde otras perspectivas críticas y no oficiales, valiéndose de las distintas herramientas de análisis para la comprobación de la hipótesis planteada.

El artículo comienza con un análisis del contexto actual definido en términos de guerra total plutogénica contra la vida planetaria, en cuanto se considera que las catástrofes presentes son el resultado de una lucha de clases por la acumulación de poder y capital que destruye todo a su paso, como medio de aseguramiento de lo que queda.

A continuación, el artículo centra su estudio en el planteamiento teórico del modelo de esta- 
do que se consolida tras los acontecimientos del 11 de setiembre de 2001, como mecanismo de gestión inmunitaria para hacer frente a ese contexto de destrucción planetaria y aniquilación de la vida. Seguidamente, el texto comienza a explicar la evolución histórica del proyecto imperial estadounidense a partir de esta fecha, y su vinculación con este modelo de estado securitario.

El artículo continúa con un análisis de la evolución de las tecnologías de la vigilancia y el control total de las poblaciones que caracterizan al modelo de estado policiaco-militar que se consolida a partir del proyecto imperial estadounidense y concluye con lo que se considera como una "crítica argifonte" o "anti-securitaria" contra ese modelo de estado, sin la necesidad de rehuir del pensamiento abismal ni de la catastrófica situación que define nuestra existencia actual. Por el contrario, se sitúa en esa realidad abrumadora y chocante para descubrir quiebres y resistencias, para encarnarlas, in-corporarlas, y así poder atravesar esta época que vivimos y al modelo de seguridad total que se nos impone.

\section{Bienvenidos al Abismo. Apuntes sobre la guerra total plutogénica contra la vida en el planeta.}

Más que realizar el ejercicio decolonial de promover una reflexión desde una suerte de "pensamiento post-abismal", la intención de estas palabras pretende todo lo contrario: hundirnos en el abismo de la realidad. Lo que aquí se pretende es una filosofía de la situación que piense el estado de sitio y la fortificación de una máquina totalizante de seguridad. Situarnos en el "más acá de lo abismal" nos permite comprender que la serie de destrucciones ecológicas, desplomes económicos, hambrunas, epidemias, guerras, latigazos climáticos, exterminios, y demás catás-trofes, ocurren en este preciso momento, que son, además, de carácter plutogénico ${ }^{1}$ más que antropogénico, es decir, provocadas desproporcionalmente por una muy reducida porción de la humanidad, con injustificada e irracional posesión de poder y capital.

Este contexto de colapso solo puede compararse con la devastación causada por "el asteroide gigante que chocó con la Tierra hace sesenta y cinco millones de años, barriendo en un instante geológico la mitad de las especies de entonces" (Leakey y Lewin, 1997: 260). De proporciones globales, esta catástrofe plutogénica es considerada como una nueva fase de extinción masiva de especies, sumándose a otras anteriores, pero adquiriendo una velocidad que las supera.

Asumir una reflexión situada en el más acá de lo abismal cumple una función política, que tiene por objetivo poder disputarle a los poderosos "la inteligencia estratégica del presente" (Co-mité Invisible, 2015: 18), lo que nos permitirá acceder a "la visión general de las operaciones en curso" (Comité Invisible, 2015:18), que deben ser comprendidas en el marco de una guerra total contra la vida en el planeta, tal como lo constatan las palabras de Ceballos, Ehrich y Dirzo, para quienes el planeta está experimentando,

un gran episodio de disminución y extirpación de poblaciones, que tendrá consecuencias negativas en cascada en el funcionamiento y servicios de los ecosistemas que son vitales para el mantenimiento de la civilización. Describimos esto como una "aniquilación biológica" para resaltar la magnitud actual del sexto evento de extinción

1- En cuanto que las destrucciones planetarias y la aniquilación de la vida son llevadas a cabo por los sectores más poderosos. En consecuencia, considero más pertinente denominar como Plutoceno a esta era de colapso mundial que son el resultado del gobierno de los ricos, o más precisamente de la emergencia y permanencia de las jerarquías y su obsesión por el poder. 
grave actualmente en curso en la Tierra (Ceballos, Ehrlich, y Dirzo, 2017: 1, Énfasis BGH).

La sentencia de estos científicos no da cabida a ambigüedades, ni a ligerezas terminológicas, "es importante usar un lenguaje muy fuerte porque lo que está pasando es gravísimo" (Pais, 2017), sostuvo Gerardo Ceballos cuando se le cuestionó el uso del concepto de aniquilación biológica. Aniquilar, del latín annichilare, alteración de nihil, 'nada', significa literalmente "reducir a nada" (Corominas, 1961: 52), da cuenta no sólo de una fase de un macroproceso global e histórico, la sexta extinción, sino de una acción consciente que perfectamente se relaciona con la guerra.

Específicamente, es una manifestación directa de una guerra total contra la vida, la de todos los seres que habitan el planeta, incluida la humanidad, que se hace patente en procesos claramente definidos como la deforestación, la defaunación, y la destrucción de los océanos, por citar algunos ejemplos.

En el caso de la deforestación, es decir, el proceso de destrucción de la superficie forestal del planeta, el "reducir a la nada" es harto evidente. Según el Global Forest Watch", "la pérdida de cobertura arbórea mundial, ascendió a un récord de 29,7 millones de hectáreas (73,4 millones de acres) en 2016" (Weisse y Goldman, 2017). Lo que equivale a un aumento del 51\% respecto al año anterior. Las causas de dicha devastación son los incendios forestales, la expansión agrícola, la extracción de madera, la expansión de infraestructuras y la minería.

Respecto a la fauna planetaria, la aniquilación biológica, denominada como defaunación, se estima que entre los años de 1970 y 2014, la población mundial de peces, aves, mamíferos, anfibios y reptiles disminuyó en un 60\%, según el informe Planeta Vivo 2018 del Fondo Mundial para la Naturaleza (WWF por sus siglas en inglés).

Según el estudio de Ceballos, et al (2014), la defaunación "entre los vertebrados terrestres, 322 especies se han extinguido desde 1500, y las poblaciones de las especies restantes muestran un $25 \%$ de descenso promedio en abundancia. Los patrones de invertebrados son igualmente nefastos: el $67 \%$ de las poblaciones monitoreadas muestran una disminución de la abundancia del 45\% " (Ceballos, et al, 2014: 401)

Al mismo tiempo que se lleva a cabo la deforestación y la defaunación, también se está produciendo la destrucción de hábitats como los océanos, ríos, arrecifes de coral, regiones polares, entre otros. En el caso de los océanos, por citar un ejemplo, "el $80 \%$ de la contaminación de los ambientes marinos provienen de tierra firme" (NOAA, $\mathrm{s} / \mathrm{f}$ ) especialmente por plásticos y desechos radioactivos, que han convertido a los océanos en cementerios atómicos

Los ejemplos antes mencionados escuetamente evidencian el acelerado proceso aniquilador que amenaza a la vida en el planeta, llevada a cabo por un reducido grupo de humanos y su modelo de producción, ya que, como señaló Clausewitz, "en todas las circunstancias debemos considerar a la guerra no como algo independiente, sino como un instrumento político" (2004: 49).

Al ser la guerra un instrumento político, debe entonces comprenderse a la aniquilación biológica que caracteriza a nuestra era, como parte de un proyecto político que se define a partir de una lógica de la acumulación por destrucción ${ }^{3}$, que consiste en la devastación de territorios,

2- El Global Forest Watch es una iniciativa del nada confiable World Resources Institute y sus socios USAID, GOOGLE, Cargill, BID, entre otros organismos y corporaciones que son parte de las extensiones tentaculares del imperialismo estadounidense y sus aliados, lo que implica que tras estas preocupaciones por la protección de los bosques y otros ecosistemas, se encuentran intereses específicos que pretenden el control de los bienes comunes globales, bajo la excusa de la ayuda para una adecuada gestión, como sucede con la iniciativa del Banco Interamericano de Desarrollo para la gestión de los bosques en América Latina y el Caribe. A pesar de esto, los datos que proporcionan ponen en evidencia la aniquilación biológica como un instrumento político.

3- En alemán existe la palabra Raubmord, que se aproxima vagamente a la idea de la acumulación por destrucción, dando cuenta de 
exterminios sistemáticos, el desgarre de la sociedades, sometidas al horror para su pacificación, a la vez que las fuerzas armadas imperialistas, corporaciones y otros instrumentos imperiales a su disposición (ONG, Organismos Intergubernamentales, Instituciones, ejércitos paramilitares, organizaciones criminales y terroristas), en conjunto con sus gobiernos y oligarquías locales custodian los recursos y los territorios estratégicamente más importantes.

Hace veinte años, Susan George en su libro Informe Lugano advertía con gran lucidez el curso de esas políticas de aniquilamiento en manos de los grupos de poder, con el propósito de conservar al capitalismo en el siglo XXI: "no podemos sostener el sistema liberal de libre mercado $y$, simultáneamente, seguir tolerando la presencia de miles de millones de personas sobrantes" (George, 2003: 83).

La solución planteada no es nueva. Ha sido desarrollada a lo largo de los años, incluso de los siglos, presentada como cuestiones de "selección natural", problemas de sobrepoblación, darwinismo social, economía de la vida, biopolítica, y ahora "gestión planetaria". Su precursor, señala Carl Amery, fue Adolf Hitler, y en ella la minoría encargada de dicha gestión,

habrá de asumir la responsabilidad, habrá de cargar con el fardo más pesado del hombre ( $\mathrm{sic}$ ) blanco, no sólo el de tutelar un mundo lleno de medio niños, medio diablos, sino además la de responsabilizarse de la biosfera, conservando, eso sí, ese nivel de vida propio tan merecido y empleando todos los medios que ofrecen la ciencia y la técnica (Amery, 2002:169).

Este pesado fardo no es ningún secreto a voces, ni mucho menos una exagerada imagen literaria para recrear un escenario de alguna novela de ciencia ficción. Es parte de los cálculos políticos para mitigar la devastación plutogénica que denotan el giro necropolítico de la "gestión planetaria" para el siglo XXI, como lo constatan confirman las palabras de Zbigniew Brzezinski, entonces asesor del expresidente estadounidense Barack Obama, en su discurso de 2008 en la Chatham House en Londres, para los grupos de poder británicos: "Hoy es infinitamente más fácil matar a un millón de personas que controlar a un millón de personas. Es más fácil matar que controlar" (Brzezinski, 2008).

Esta guerra total contra la vida es llevada a cabo mediante el uso y abuso del poder militar/ policial del Argos Panoptes, la máquina estatal para el control y pacificación de sus poblaciones, y para la destrucción de sus potenciales enemigos.

\section{Anatomía del Argos Panoptes. Apuntes sobre el monstruo estatal.}

Argos Panoptes, literalmente "de todos los ojos", es una figura de la mitología griega que tenía múltiples ojos, presente en el mito de ĺo, la ninfa convertida en ternera y custodiada por él para mantenerla lejos de Zeus. Argos Panoptes era "el guardián infalible encargado de vigilar a la vaca por orden de Hera" (Villagra, 2013: 1).

un tipo de crimen en el que el robo se combina con el asesinato. En nuestro caso, la acumulación no sólo genera desposesión, sino que en su mismo accionar acumulativo, destruye, no como consecuencia directa, es un mismo movimiento. En palabras de Hannah Arendt, "la más radical y la única forma segura de posesión es la destrucción, porque sólo lo que hemos destruido será nuestro de seguro y para siempre" (Arendt, 1979: 145). 
Este concepto-metáfora es la alegoría perfecta para representar al modelo de Estado como máquina de seguridad total que se consolida después de los acontecimientos del 11 de setiembre de 2001 en los Estados Unidos que, como momento imperial, justificaron la reorganización del poder en todas las escalas. Por tanto, el Argos Panoptes es una adecuación para estos tiempos catastróficos del simbólico "Leviatán" recreado por Thomas Hobbes en 1651 y que fundamenta al conocido modelo hobbesiano de organización del poder y la pacificación de las poblaciones.

De acuerdo con Giorgio Agamben "el hecho de que el Leviatán era un artefacto, comparable, como sugiere Hobbes en la introducción, a "Autómatas (motores que se mueven por muelles y ruedas como un reloj)", era perfectamente conocido; Sin embargo, (...) lo que está en cuestión aquí no es un artilugio mecánico, sino un dispositivo óptico (Agamben, 2015: 38, énfasis del autor).

El Argos Panoptes es la figura más próxima a esa idea del Estado como un dispositivo de vigilancia total, una radicalización del modelo estatal hobbesiano, cuya razón de ser es el garantizar la seguridad mediante el control total de sus poblaciones. En definitiva, una máquina de gestión inmunitaria para el actual contexto plutogénico de destrucciones planetarias y aniquilación de la vida.

La concepción del Estado hobbesiano es, ante todo, un modelo securitario. Así ha sido comprendido y asumido por el poder y sus teóricos, como Carl Schmitt, para quien el Estado es "una gran máquina, un mecanismo gigantesco al servicio de la seguridad de la existencia física terrenal, de los hombres (sic) que él domina y protege" (Schmitt, 2008: 95, énfasis BGH).

Como máquina de gestión inmunitaria que garantiza la protección del orden social y sus modos de producción, su papel está centrado en lo que Mihail Bakunin definió como la "organización del poder" (Bakunin, 2010: 119). Este modelo de máquina total que (re) organiza las relaciones de poder y la producción espacial de la seguridad, está definido, por ese carácter inmunitario, es decir, está constituido por una serie de aparatos administrativos y de dispositivos de seguridad funcionales

Con fin de estabilizar los intereses cambiantes y en conflicto de los distintos individuos y grupos sociales. Es por eso que desde el principio se ha hablado en términos institucionales de Estado-máquina, Estado-aparato, Estado-mecanismo y Estado-administración" (Ochoa, 2009: 50).

Mientras que su carácter de gestión inmunitaria está definido a partir de la coordinación, interoperabilidad e interacción entre los distintos dispositivos que garantizan el aseguramiento del orden social. Con esto, al

Gestionar los riesgos que plantea la desintegración social conlleva a nuevas formas de acción estatal que se están uniendo al proyecto hegemónico post-bienestar: la securitización. A medida que este proyecto gana impulso, somos testigos de tres transformaciones fundamentales en la naturaleza del Estado: primero, el control del crimen se convierte en el paradigma preeminente para el control social; segundo, la política social y el bienestar se criminalizan progresivamente; mientras que, tercero, las funciones del Estado se distribuyen cada vez más a través de un conjunto de actores estatales y no estatales. (Hallsworth; Lea, 2011: 144).

Con la consolidación de este tipo de Estado-Máquina inmunitaria, "todos los vínculos y lazos comunitarios son disueltos. Individuos atomizados se encuentran reunidos por su miedo, hasta 
que la luz del entendimiento resplandece y se constituye un consenso jurídico con base en la sumisión general e incondicional al poder más fuerte" (Schmitt, 2008: 93).

Si es el miedo, en específico el miedo a la muerte, es lo que reúne a los individuos atomizados y lo que les obliga a la sumisión incondicional al poder soberano, mediante un supuesto pacto, entonces, la máquina de gestión inmunitaria, garantiza, no tanto la protección de los individuos temerosos, sino la continuidad de esa sumisión y obediencia.

En consecuencia, la razón de Estado está definida por la máxima "protejo, luego obligo", como señala Schmitt (2009), entonces para una eficaz protección ante las distintas amenazas y una verdadera sumisión incondicional a un poder soberano, el Estado-máquina opera como un "dispositivo óptico", esto es, como un aparato de vigilancia y control de poblaciones enteras, con el objetivo de instaurar la seguridad y el orden público.

Al definirse al Estado como una máquina de gestión inmunitaria, se entiende que gestiona una serie de dispositivos mediante los cuales se asegura el orden social establecido y se protege la acumulación de poder y capital.

En consecuencia, el Argos Panoptes, el modelo estatal-securitario para el siglo XXI, se consolida como una especie de panóptico compuesto por todos los eslabones de la sociedad, desde el ciudadano hasta las altas esferas del Estado, y sus fuerzas policiaco-militares, conformando una unidad política total, movilizada en torno a la idea de un combate total contra enemigos, también totalizados.

Se comprende entonces, que los dispositivos de seguridad del Argos Panoptes en el contexto actual tienen por objetivo el control total, mediante la vigilancia permanente para garantizar y asegurarse del cumplimiento de cierta seguridad cognitiva, es decir conductas socialmente aceptadas por parte de sus ciudadanos. En palabras de Günther Jakobs, "cualquiera que quiera ser tratado como persona en Derecho, ha de ofrecer a cambio una cierta garantía de que se comportará como una persona en Derecho4" (Jakobs, 2009: 25).

Las personas que no garanticen dicha seguridad cognitiva, en el marco de esta nueva forma de gobierno, suponen un peligro para el orden social y por tanto se le considera como un enemigo. Jakobs, sostiene, por tanto, que "el Estado debe poder penar irremediablemente «conductas especialmente peligrosas»" (Jakobs, 2009: 39), en consecuencia, "se hace todo lo posible para combatir el peligro, y cuando se le combate todo está en regla" (Jakobs, 2009: 36).

En otras palabras, quien no pueda garantizar una seguridad cognitiva, en su relación con los dispositivos de seguridad, se considera que padece de afasia jurídica, en suma, afirma Xacobe Bastida,

Produce ruido, no enunciados susceptibles ni tan siquiera de corrección. Por seguir utilizando este símil lingüístico, el ciudadano que delinque habla mal nuestra lengua $y$, en consecuencia, el Derecho intenta enseñarle su uso correcto reafirmando la validez del patrón ortográfico que usa la mayoría. El enemigo, en cambio, habla otro idioma y, además, da muestras de no querer aprender el nuestro. Por eso, al enemigo, como dice Jakobs, no se le comunica nada, simplemente se le combate (Bastida, 2006: 280).

La consolidación del Argos Panoptes en el contexto de la guerra total conlleva al surgimiento de un tipo de derecho que normaliza la anomia, llamado derecho penal del enemigo, corriente del

4- Para Jakobs, "una persona en Derecho no es, por ejemplo, como a menudo se afirma, un individuo humano o un sujeto, esto es, un individuo consciente de sí mismo, sino el portador de un rol, o más exactamente, el destinatario del Derecho" (Jakobs, 2009: 25). 
derecho que se ha comenzado a permear los ordenamientos jurídicos estatales. El derecho penal del enemigo es,

Aquel sector del ordenamiento jurídico-penal, en el que la pena no significa un reproche hacia la conducta del autor, sino que actúa como un mecanismo de aseguramiento frente a autores especialmente peligrosos. En este sentido, mediante el derecho penal del enemigo, el Estado no habla con sus ciudadanos, sino amenaza a sus enemigos (Cancio y Gómez-Jara, 2006: xvii).

Respecto a lo anterior, se destaca desde este tipo de derecho, la diferenciación entre ciudadanos y enemigos, los primeros considerados como personas en derecho, siempre y cuando se "comporten" como personas en derecho. Mientras que los segundos refieren a humanos que han sido privados de su condición de personas, y con ello, carentes de cualquier tipo de derecho que les proteja, lo que pone de manifiesto el carácter político de esta rama del derecho, que conlleva a la persecución, criminalización, violación flagrante de Derechos Humanos mediante tortura y la eliminación sistemática de cualquier disidencia. Cabe recordar que la enemistad es la esencia de la guerra, y el Estado, en su condición de unidad política le es atribuido inherentemente el ius belli, es decir, "la posibilidad real de, llegado el caso, determinar por propia decisión quién es el enemigo y combatirlo" (Schmitt, 2009: 74).

Este tipo de combate contra lo que se considera "enemigo", transmite un mensaje en el que "se refuerza como prejuicio la convicción de que un mundo que se desordena se puede ordenar con disciplina impuesta con represión indiscriminada" (Zaffaroni, 2006: 74). Esta corriente o rama del derecho no es otra cosa que un instrumento para la pacificación de las poblaciones y la eliminación sistemática de categorías de personas consideradas como enemigas.

Al concebirse como una pacificación necesaria para garantizar el orden social, justifica la suspensión del mismo orden, en cuanto que "un Estado que deba y quiera proteger a sus ciudadanos frente a delitos previsibles no puede evitar dicha institución" (Jakobs, 2009: 32). Según Jakobs, al encontrarse amenazado el Estado de Derecho, este "ha de dar un paso atrás, precisamente para evitar que el Estado de Derecho sucumba por completo" (Jakobs, 2009: 15). En otras palabras, la pacificación que se promueve está determinada por la excepcionalidad, impuesta a partir de los acontecimientos del 11 de setiembre de 2001.

\section{El "momento imperial": El 11 de septiembre de 2001 y el asalto al poder global}

Lo acontecido el 11 de setiembre de 2001 puede ser comprendido como un "momento imperial", aprovechado por los Estados Unidos para quebrar con el statu quo internacional construido desde la Segunda Guerra Mundial, para la consolidación de su proyecto imperialista para el siglo XXI, considerado desde las altas cúpulas del poder estadounidense como la era del dominio global de su país.

Este acontecimiento va a implicar también una aceleración de la consolidación del modelo estatal-securitario hobbesiano, gracias a los avances tecnológicos en materia de vigilancia y guerra, que se venían desarrollando desde décadas anteriores.

Este momento imperial tuvo, además, implicaciones espaciales en todas las escalas, desde lo planetario hasta lo molecular, debido, principalmente, al hecho de que "todo orden social es 
una ordenación del espacio y está condicionado por las concepciones que se tengan del espacio" (Campderrich, 2007: 10).

La quiebra del orden internacional por medio de la excepcionalidad y la guerra total a partir de este acontecimiento, también tenía por objeto un "cambio radical y acelerado en el horizonte espacial humano y en su modo de concebir la dimensión del espacio" (Campderrich, 2007: 10), lo que en términos del lenguaje imperialista puede comprenderse como una "revolución espacial".

El proyecto imperial de los Estados Unidos ha conllevado también una revolución espacial con explícitas consecuencias para el imaginario geopolítico del siglo XXI y la Política Internacional. Esta reconfiguración espacial es guiada por la estrategia de destrucción imperial RumsfeldCebrowski que divide al mundo en dos bloques claramente diferenciados y antagónicos. Por un lado, un núcleo funcional e integrado (Functioning Core); y, por el otro, un espacio no integrado (Non-Integrating Gap).

Para lo cual el primer grupo se regiría por el nuevo derecho internacional emergente tras la quiebra del viejo nomos internacional, mientras que el segundo grupo representaría, literalmente un abismal espacio de excepcionalidad, con estados fallidos que han perdido el control soberano sobre sus territorios nacionales, ahora disputados entre distintos actores, que van desde grupos criminales, cárteles de la droga, y el mismo estado debilitado tras años de desmantelamiento por las políticas neoliberales dictadas desde organismos internacionales que operan como extensiones tentaculares imperiales.

La transformación del mapa mundial fue parte de la estrategia imperial desde un inicio, el hecho de que a diez días después del 11 de setiembre de 2001 el Pentágono ya tenía una lista de países a los cuales atacar sin que éstos tuvieran vínculo alguno con los "ataques terroristas", como lo señaló el general estadounidense Wesley Clark en su entrevista con Amy Goodman para el medio Democracy Now (Goodman, 2007), así como el hecho de que a partir de la publicación de la Estrategia de Seguridad Nacional de 2002, los Estados Unidos dejó de reconocer el principio de soberanía absoluta de los Estados, dan cuenta de la intencionalidad de esta revolución espacial llevada a cabo por los estadounidenses en su asalto imperial.

Ahora bien, esta revolución espacial se ha realizado en todas las escalas, desde la planetaria hasta la molecular. Esto significa que el proceso de imperialización tiene también consecuencias directas sobre las ciudades y sobre los cuerpos de las poblaciones. Para comprender este vínculo transescalar basta tener presente las palabras de Thomas Barnett cuando se refirió al acontecimiento del 11 de setiembre de 2001 como un "regalo maravilloso" que los Estados Unidos debían aprovechar para instaurar un nuevo conjunto de reglas del Derecho Internacional, que definirían en adelante las Relaciones Internacionales y garantizarían la seguridad nacional total de los estadounidenses.

A lo cual, Barnett pone en evidencia el carácter totalizante de la estrategia norteamericana al mencionar cómo la producción espacial de la seguridad debe ampliarse hacia los distintos espacios de la ciudad para que no puedan ser aprovechados por los potenciales enemigos, y en consecuencia sobre los cuerpos de las personas. En sus palabras,

No teníamos suficientes conjuntos de reglas en ciertas áreas de nuestras vidas (por ejemplo, seguridad aeroportuaria, políticas de visas), y esas brechas en los conjuntos de reglas podrían ser fácilmente explotadas por aquellos que no se adhieren a nuestros conjuntos de reglas generales (Barnett, 2004: 27).

Barnett hace referencia de forma indirecta al plan estratégico Joint Vision 2020, precisamente porque para cubrir esos "vacíos" presentes en ciertas áreas de nuestras vidas y que pueden ser 
aprovechados por los potenciales enemigos de los Estados Unidos, entonces se hace necesario considerarlos como objetivos militares, adquiriendo un carácter estratégico en el marco de una guerra total. Es en este punto en el que se encuentran la estrategia del Full Spectrum Dominance, y la doctrina de la Guerra Centrada en Redes (Network Centric Warfare) planteada también por Arthur Cebrowski, que van a posibilitar la consolidación de un modelo estatal de seguridad total, el Argos Panoptes, tal como se lee en el plan estratégico,

La evolución de la tecnología de la información nos permitirá integrar bajo incremento las formas tradicionales de operar con la inteligencia, vigilancia y reconocimiento sofisticados de toda fuente en una campaña informativa totalmente sincronizada (citado en González, 2014: 116).

La revolución de los asuntos militares por la que tanto abogaron los neconservadores del Proyecto para el Nuevo Siglo Estadounidense, resultado de la experimentación y desarrollo de nuevas tecnologías "Tendrá profundas implicaciones sobre cómo se libran las guerras, qué tipo de armas dominarán el campo de batalla e, inevitablemente, qué naciones disfrutan de preeminencia military (PNAC, 2000: 50).

Esta transformación de la guerra y de los medios que utiliza ha significado, en consecuencia, una mutación de los teatros de operaciones militares, es decir, de los espacios en los que se materializa el combate y sobre el cual se despliegan y aplican todos los dispositivos de seguridad y guerra. Dicho de otra forma, las guerras en el siglo XXI se disputan en las ciudades, en el ciberespacio, en el espacio exterior y, con más virulencia, en los cuerpos de las poblaciones, para el cual era necesario radicalizar a la máquina de gestión inmunitaria para el cumplimiento de estas operaciones.

Al considerarse estos "espacios" como objetivos militares, su control y vigilancia pasan a un primer plano. Por tal motivo, la imperialización, en este caso entendida como la producción espacial de la seguridad está estrechamente vinculada con la estrategia de Dominio del Espectro Completo y de la Guerra centrada en Redes, en cuanto que los cuerpos y las ciudades pasan a ser informatizados mediante la construcción de una red global con interconexiones "para manejar y proveer la información a demanda de guerreros, hacedores de política y gente de apoyo" (citado en González, 2014: 116-117). A lo que Sergio González considera que es el "punto de ensamblaje entre la vida militar y la vida civil: las personas, sus prácticas y modalidades de consumo vigiladas a través de Internet y otras plataformas" (2014: 117).

Esta red global de vigilancia total para el dominio de espectro completo fue expuesta en junio de 2013 por el ex funcionario de la CIA y de la Agencia de Seguridad Nacional (NSA, en inglés), Edward Snowden quien hizo públicos una serie de documentos clasificados sobre los programas de espionaje desarrollados por los Estados Unidos para interceptar y espiar las telecomunicaciones en cualquier parte del mundo, destacando la vigilancia sistemática a líderes mundiales.

Estas filtraciones de Snowden se suman a las realizadas por Chelsea Manning, vía Wikileaks, desde 2010 sobre las atrocidades cometidas por los Estados Unidos en Afganistán e Irak, haciendo patente que esta es la fase más mortífera del imperialismo estadounidense.

En definitiva, todo lo antes mencionado amplía la comprensión de lo que ha representado la imperialización llevada a cabo por los Estados Unidos, un proceso que también ha significado la producción espacial a escala local y corporal, haciendo evidente que nos encontramos en medio de una guerra imperial total global contra las poblaciones y la naturaleza, como forma de gestión planetaria que pretende el control de los recursos que se agotan aceleradamente, a la vez que reducen el tamaño de la población mediante el exterminio sistemático, dando la bienvenida a un 
mundo distópico que escapa a la imaginación de cualquier autor de ciencia ficción.

\section{El mundo que Orwell jamás imaginó.}

Una de las principales propuestas del documento del Proyecto para el Nuevo Siglo Estadounidense, como se mencionó anteriormente, es lo que refiere a la revolución de los asuntos militares para asegurar la superioridad a largo plazo de las fuerzas armadas estadounidenses y afrontar los nuevos retos geopolíticos y tecnológicos. Para los halcones, la revolución de las tecnologías de la información y de la comunicación cambiaría la naturaleza misma de la guerra.

Esto es importante, principalmente porque la revolución de los asuntos militares en los términos que los halcones lo expusieron, hizo realidad lo que no sucedió en ningún otro periodo de la historia bélica mundial, la posibilidad de llevar a cabo una guerra verdaderamente total. Según Armand Mattelart,

Ya sea en el campo de batalla de los ejércitos o en la sociedad y en el mundo, como campo de batalla, se trata de enlazar todos los sistemas mediante una red de comunicaciones e informaciones de tal modo que la cabecera del sistema de sistemas tenga un conocimiento preciso de cada uno de los teatros de operaciones, de sus actores y sus trayectorias, con el fin de prevenir proyectos y acciones del nuevo enemigo global y ajustar la réplica en tiempo real (Mattelart, 2009: 179).

Uno de los principales aspectos de la estrategia del Dominio de Espectro Completo, es la superioridad de la información, definida como "la capacidad de recolectar, procesar y diseminar un flujo constante de datos mientras se socava u obstruye que el adversario disponga de la misma habilidad" (citado en González, 2014: 115).

Para alcanzar esa superioridad informática fue necesario obtener toda la información posible, proveniente de individuos, sistemas de información, organizaciones, gobiernos. Para lo cual fue necesaria la masificación del Internet, el uso de teléfonos móviles, y el desarrollo de las tecnologías de la vigilancia, lo que representó una transformación no sólo en las relaciones entre las personas, sino también en los sistemas de vigilancia que se han ido perfeccionando desde el siglo XX. Según Reg Whitaker,

Cualquier adelanto técnico exigía nuevas invenciones técnicas que permitiesen interceptar y leer lo que pretendía comunicarse: tras el teléfono y el telégrafo, vino la interceptación de las líneas telefónicas y telegráficas; tras la comunicación radiotelefónica, se hizo necesario desarrollar nuevas técnicas capaces de recoger las señales del «éter»" (Whitaker, 1999: 19).

Toda esta revolución de los asuntos militares no comenzó propiamente con el acontecimiento del 11 de setiembre de 2001, que fungió más como un acelerador y masificador de estas tecnologías de la vigilancia y el control de las poblaciones. Según Duncan Campbell, "desde prin- 
cipios de los años 90 se han desarrollado sistemas Comint ${ }^{5}$ (Communications Intelligence, BGH) rápidos y complejos para interceptar, filtrar y analizar todas las formas de comunicación digital que se utilizan en internet" (citado en García, 2003: 122).

Fue durante la era Clinton que comenzó el auge por incorporar al ámbito de lo policiaco-militar las tecnologías de la vigilancia masiva, el rastreo y la intercepción de las telecomunicaciones, bajo la excusa del combate al narcotráfico. El mejor ejemplo de ello, fue la aprobación en 1994 por parte del Congreso estadounidense de la Ley 103-414, conocida como Communications Assistance for Law Enforcement Act (CALEA), que amplió las potestades de las "agencias para la obligatoriedad violenta de la obediencia de la ley" (Law Enforcement Agencies ${ }^{6}$ ) para conducir operaciones de intercepción y vigilancia masiva de las comunicaciones.

Otro ejemplo fue la creación de bases de datos creados para monitorear el abuso de las drogas de prescripción que

Recopila y almacena los detalles de las recetas médicas de las personas, que luego pueden ser verificadas por la policía, las farmacias y los médicos para detectar patrones "sospechosos". Estas bases de datos son financiadas por el gobierno federal, que también las "incita" a vincular las bases de datos estatales en una sola base de datos nacional distribuida (Stanley, 2011).

Por otra parte, en abril de 2000, el FBI comenzó a instalar masivamente en los Proveedores de Servicio de Internet (ISP), el programa "Carnivore", desarrollado desde los años 90, "capaz de hacer un seguimiento de todo el tráfico de datos de un usuario concreto, incluida su trayectoria de navegación" (García, 2003: 125).7

Al final, la importancia de todas las formas de vigilancia que se fueron desarrollando desde la guerra contra las drogas sirven para un mismo objetivo: "señalar los objetivos, el lugar donde se encuentran y/o centrarse en esos objetivos" (Bauman y Lyon, 2013: 99).

El acontecimiento del 11 de setiembre de 2001, fue medular en este proceso de totalización de la vigilancia, no sólo porque justificó la ampliación de poderes del gobierno estadounidense para espiar a sus ciudadanos, sino que significó la exportación a nivel global de una racionalidad securitaria, una suerte de estilo de seguridad estadounidense (American way of security), que fue asumida por todos los gobiernos del planeta, ya sea como forma de integración a la estrategia imperial estadounidense o para contrarrestarla.

\footnotetext{
5- Según García Mostazo, "la actividad Comint consiste en obtener información secreta mediante la interceptación de las comunicaciones internacionales. Este tipo de operaciones de espionaje empezaron a producirse al inicio del siglo pasado" (García, 2003, p. 25).

6- La palabra enforce es traducida al español como "hacer cumplir" (ver la edición de 2007 del diccionario Larousse español-inglés, página 153), por lo que enforcer es traducido como una especie de "ejecutor". Sin embargo, estas traducciones no dan cuenta del uso de la fuerza que va implícito en la palabra en inglés, más próxima a la obligatoriedad a la obediencia mediante la fuerza o la amenaza de su uso. El diccionario etimológico del inglés en línea, describe a la palabra como una acción que se ejerce mediante la violencia: "from Old French enforcier "strengthen, reinforce; use force (on), offer violence (to); oppress; violate, rape" (OED, s/fb). Por tanto, el enforcer refiere a "alguien que obliga, restringe o urge", en otras palabras, quien intimida mediante la violencia, "a violent intimidator" (OED, s/fc). En el caso de la expresión law enforcement, eufemísticamente traducido como "aplicación de la ley" debe, entonces, entenderse más como la obligatoriedad violenta de la obediencia a la ley (entiéndase a la autoridad).

7- Es de gran importancia destacar que desde 1994 con la aprobación de la Ley de Asistencia en Comunicaciones para los Cuerpos de Seguridad (Communications Assistance for Law Enforcement Act, CALEA), se obligó a las empresas colaborar estrechamente con los aparatos de seguridad estadounidenses. Según García Mostazo, "esta norma establece la obligación legal de los operadores de telecomunicaciones y los fabricantes de equipos informáticos de incluir dispositivos de vigilancia en toda la red telefónica de Norteamérica" (García, 2003: 125).
} 
A partir de este acontecimiento, la seguridad y la guerra retomaron su rol preponderante como ejes articuladores del orden político y, en consecuencia, de la producción espacial de las ciudades, ahora saturadas de distintos dispositivos de vigilancia que monitorean cada movimiento que se realiza en los espacios urbanos, bajo la excusa de prevenir que cada punto ciego sea aprovechado por potenciales enemigos del orden imperial. Desde entonces, apunta José Miguel G. Cortés,

El entorno construido es un medio primario para las técnicas de establecimiento, legitimación y reproducción de una determinada mirada, de una ideología que organiza cualquier estructura social o vital, desde la casa a la ciudad. Toda autoridad, toda práctica de poder, tiene necesidad de establecerse, de seducir y/o de intimidar a través de sus símbolos" (Cortés, 2010: 9)

Esto es lo que ha significado la estrategia de Dominio de Espectro Completo en lo que respecta a la producción espacial de la seguridad y la consolidación del modelo estatal-securitario que aquí denomino como Argos Panoptes: ciudades hipervigiladas y controladas por distintos dispositivos de seguridad, todos integrados a la red global, en beneficio del proceso de imperialización llevado a cabo por los Estados Unidos, que, gracias a las bases de datos, la Big Data, puede clasificar a las personas de las distintas ciudades y determinar si son individuos potenciales peligros, a la vez que la hipervigilancia opera también como dispositivos pedagógicos para inscribir el orden imperial en las poblaciones, induciendo a las personas,

A un estado de visibilidad permanente y que asegura el funcionamiento automático del poder, una tecnología que se utiliza sin ruido, que sutilmente se incrusta en las actitudes y en los hábitos personales. El objetivo es conseguir que el individuo se sepa bajo control, al tiempo que modifica las maneras sociales de relacionarse y origina prácticas que tratan de convertir la multitud inconexa e indiferenciada en una colección de individuos reconocibles y marcados" (Cortés, 2010: 23).

La totalización de la vigilancia y el control en el contexto actual, tras los acontecimientos del 11 de setiembre de 2001, tienen por objetivo velar porque, en su relación con los cuerpos, se garantice cierta seguridad cognitiva, es decir conductas socialmente aceptadas. En palabras de Günther Jakobs, "cualquiera que quiera ser tratado como persona en Derecho, ha de ofrecer a cambio una cierta garantía de que se comportará como una persona en Derecho" (Jakobs, 2009: 25).

Tomando en consideración que vigilar, controlar y clasificar toda la información que genera una sola persona en su transitar por los espacios de las ciudades altamente vigiladas, así como toda la que produce en sus interacciones en el Internet y las redes sociales, es tan abrumadora que resulta casi imposible para los Estados poder darle seguimiento a todas las personas, por lo que se podría suponer que no hay posibilidad de determinar quiénes, de toda la población, garantizan esa seguridad cognitiva, demostrando que son buenos ciudadanos, se comportan como personas en Derecho, y quienes se están organizando para contrarrestar al orden imperial. Según IBM,

8- Para Jakobs, "una persona en Derecho no es, por ejemplo, como a menudo se afirma, un individuo humano o un sujeto, esto es, un individuo consciente de sí mismo, sino el portador de un rol, o más exactamente, el destinatario del Derecho" (Jakobs, 2009: 25). 
Detectar ataques y comportamientos anómalos antes de que causen daños requiere supervisión constante y el máximo uso de los datos. Pero el mundo genera más de 2,5 quintillones de bytes de datos a diario, y el $80 \%$ de ellos no está estructurado" (IBM, 2016).

Sin embargo, esa posibilidad de fuga es cada vez más reducida debido al desarrollo de la Inteligencia Artificial (IA) utilizada para la vigilancia, especialmente después del anuncio por parte de la corporación estadounidense IBM comenzó el entrenamiento de su IA Watson para la seguridad, haciendo cada vez más real la posibilidad de tener un control casi absoluto de la información que recopilan los distintos dispositivos de vigilancia presentes tanto en el ciberespacio como en las ciudades (IBM, 2017).

Cabe destacar que, quizás de forma perversa y en directa asociación con el derecho penal del enemigo, en 2016 IBM dio la bienvenida a la era de la "seguridad cognitiva" (IT User, 2016), a la que definió como "la implementación de dos amplias funcionalidades relacionadas":

"1) El uso de sistemas cognitivos para analizar las tendencias de seguridad y convertir grandes volúmenes de datos estructurados y sin estructurar en información y después en conocimiento aplicable para habilitar la seguridad continua y mejorar el negocio; 2) El uso de tecnologías, técnicas y procesos de seguridad automatizados y basados en datos que den soporte a los sistemas cognitivos con el máximo nivel de contexto y precisión" (IBM, 2016).

La producción espacial de la seguridad llevada a cabo gracias a la máquina de gestión inmunitaria, manifiesta mediante la totalización de la vigilancia, no se conformó con la saturación de los espacios de las ciudades de dispositivos de seguridad, ni con el uso de la IA para monitorear toda la información que producimos por nuestra conectividad extrema al Internet y las redes sociales. No bastó la seguridad cognitiva para regular el libre pensamiento y los cuestionamientos al orden imperial. Los avances tecnológicos en materia de genética, han llevado a la seguridad al plano molecular, a una especie de seguridad genómica.

En 2017, una de las mayores corporaciones de la red industrial-militar estadounidense, Northrop Grumman, anunció en su informe Precision Medicine. Security and Privacy of Genomic Data que,

Hay múltiples vulnerabilidades identificadas con respecto a los datos genómicos y la exposición. Además, los riesgos recurrentes incluyen ingeniería social y hazañas, expedientes genómicos, robo de ADN y robo de datos genómicos. También existe un gran riesgo de que los datos genómicos y la investigación caigan en las manos equivocadas donde podrían crearse armas biogenómicas. Las vulnerabilidades asociadas con los datos genómicos son excelentes y requerirán controles de seguridad y privacidad mejorados y una defensa en profundidad para garantizar que estos datos estén protegidos (Darraj y McElyeam, 2017).

Esto lleva a la producción espacial de la seguridad por el Argos Panoptes a otros niveles. Es importante destacar que todo esto comienza en febrero del año 2001, cuando se publicó en revistas científicas estadounidenses la secuenciación del genoma humano por parte del Proyecto 
del Genoma Humano (Human Genome Project, HGP), iniciativa coordinada por el Departamento de Energía de los Estados Unidos y el Instituto Nacional de Salud.

La secuenciación y la cartografía completa se publicaron en 2003. Este avance respecto al genoma humano generó un desarrollo tecnológico de herramientas para poder leer e interpretar los nuevos datos. A partir de estos avances,

la genética puede considerarse como la personificación de un desarrollo más general al que contribuyen todas las tecnologías biométricas. Un desarrollo que puede caracterizarse como la informatización del cuerpo, un fenómeno relativamente nuevo en el que el cuerpo humano parece ser redefinido como una entidad hecha de información (Van der Ploeg, 2007: 44. Énfasis de la autora).

Los avances en genómica se tornan en una amenaza para la existencia al amparo de la Patriot Act, en cuanto que "al banco de datos de ADN se han incorporado datos relativos a sujetos sospechosos de terrorismo o de haber cometido delitos violentos" (Vervaele, 2007:26).

Así se interpreta lo descrito en la sección 503 de la Patriot Act, en el que se enmienda la DNA Analysis Backlog Elimination Act of $2000^{\circ}$, e incluye en las bases de datos del CODIS (Combined DNA Index System) a cargo del FBI:

Los siguientes delitos se tratarán para los fines de esta sección como delitos federales calificados, según lo determine el Fiscal General: a) Cualquier delito enumerado en la sección 2332b (g) (5) (B) del título 18, Código de los Estados Unidos; b) Cualquier delito de violencia (como se define en la sección 16 del título 18, Código de los Estados Unidos); c) Cualquier intento o conspiración para cometer cualquiera de los delitos anteriores (Congreso de EEUU, 2001).

Esta modificación que se plasma en la sección 503 de la Patriot Act, implica que en las bases de datos del CODIS, que desde su creación contenía información sobre delincuentes sexuales o condenados, así como de personas desaparecidas, se debe ampliar e incluir información genética de quienes sean considerados como terroristas, tal como se desprende del punto " $a$ ", en cuanto la sección 2332b, capítulo 113B, del título 18 del Código de Estados Unidos refiere a "actos de terrorismo que trascienden las fronteras nacionales" (Congreso de EEUU, $s / f$ ).

En definitiva, la aspiración imperial de dominación global ha conllevado a la consolidación de una máquina tecno-tentacular de gestión inmunitaria de las amenazas para un contexto de catástrofes planetarias. Un Estado policiaco-militar que garantice y proteja, en todas las escalas y espectros, considerados como nuevos teatros bélicos, y por todos los medios que dispone, la libre acumulación de poder y capital a sus corporaciones que aglutinan a su oligarquía, en cualquier parte del planeta, o fuera de él.

9- La DNA Analysis Backlog Elimination Act of 2000 es una ley que le permite al gobierno de Estados Unidos realizar análisis de ADN para usos del Combined DNA Index System (CODIS), que es la base de datos de ADN de los Estados Unidos, creada y mantenida por el FBI. 


\section{Palabras finales. Para una crítica argifonte contra el Estado de seguridad total}

En este contexto de colapso mundial, la consigna que guía a los grupos dominantes, especialmente en Estados Unidos, es que no hay posibilidad de abandonar el modo de producción capitalista como medida para frenar la destrucción planetaria y la aniquilación biológica. Pensar en desconectarse de este sistema es considerado como terrorismo. En palabras de Thomas Barnett, "la única manera en que Estados Unidos puede lograr realmente la seguridad estratégica en la era de la globalización es destruir la desconectividad" (Barnett, 2004: 285). El capitalismo debe continuar a costa, incluso, de la sobrevivencia de las distintas formas de vida en el planeta.

La crítica contra el Argos Panoptes es fundamental para comprender que el estado, como máquina de gestión inmunitaria opera en desmedro de toda posibilidad de comunidad. La seguridad es la negación de todo contacto. Por tanto, la crítica contra el monstruo, debe asumir una actitud de argifonte -el asesino de Argos-, es decir, contestataria a los poderes policiaco-militares del Estado y a la existencia sitiada que buscan imponernos.

Por ello, criticar al modelo de Estado de seguridad que se consolidó con los acontecimientos del 11 de setiembre de 2001 en Estados Unidos, es hacerlo contra la dominación, contra la policialización de la existencia, el estilo de vida del nuevo orden imperial, la informatización de los cuerpos, la vigilancia total, el encierro y la necesidad de autoridad.

Se hace urgente el desarrollo de una crítica a la razón securitaria que define a este modelo de estado, especialmente en un contexto en el cual, producto de la pandemia global de la COVID-19, los gobiernos se han valido de los distintos instrumentos tecnológicos de la máquina de gestión inmunitaria, para una mayor vigilancia de las poblaciones, bajo excusa de un necesario control del brote pandémico.

En definitiva, ante la consolidación del Argos Panoptes y la guerra total contra la vida, es importante recordar las palabras de Günther Anders: "estamos en peligro de muerte por actos de terrorismo perpetrados por hombres (sic) sin imaginación y analfabetos sentimentales que son hoy omni-potentes" (2007: 160). El dilema que se nos presenta en este contexto de catástrofes por responsabilidad de las jerarquías y las estructuras de poder, es, parafraseando al mismo Anders, "¿cómo detener a quienes no se detendrán ante nada?" $Y$, en consonancia a esta cuestión planteada por Anders, vale preguntarse: ¿Cómo hacer crítica a la dominación y a la imperialización de los territorios, cuando se impone como garantía de sumisión y obediencia, la constante y permanente seguridad cognitiva de toda la población, mediante el control y la vigilancia total en todos los espacios por los que transitamos o convivimos en esta era plutogénica de acelerada destructividad y consolidación de Estados policiales?

\section{Referencias bibliográficas}

Agamben, G (2015). Stasis. Civil War as a political paradigm. Trad. Heron, N. California: Stanford University Press.

Amery, C. (2002). Auschwitz, ¿comienza el siglo XXI? Hitler como precursor. Trad. García, C. Madrid, España: Turner / Fondo de Cultura Económica.

Anders, G. (2007). Filosofía de la situación. Madrid, España: Los libros de la Catarata.

Arendt, H. (1979). The origins of totalitarism. New York, Estados Unidos: Harvest/HBJ Book.

Bakunin, M. (2010). Dios y el Estado. Buenos Aires, Argentina: Terramar.

Barnett, T. (2004). The Pentagon's new map. War and peace in the twenty-first century. New 
York, Estados Unidos: Berkley Books.

Bastida, X. (2006). Los bárbaros en el umbral. Fundamentos filosóficos del Derecho penal del enemigo. En Cancio, M; Gómez-Jara, C. (2006). Derecho Penal del Enemigo. El discurso penal de la excepción. V. 1. Buenos Aires, Argentina: Euros Editorial.

Bauman, Z; Lyon, D. (2013). Vigilancia Líquida. Buenos Aires, Argentina: Paidós

Brzezinski, Z. (2008). Transcripción del Discurso en Chatham House, noviembre de 2008. En línea: https://www.bibliotecapleyades.net/sociopolitica/sociopol_brzezinski03.htm (revisado el 16/4/2020).

Campderrich, R. (2007). "Tierra y Mar: historia, técnica, legitimidad". En Schmitt, C. (2007). Tierra y Mar. Una reflexión sobre la historia universal. Trad. Fernández-Quintanilla, R. Madrid: Editorial Trotta

Ceballos, G; Ehrlich, P; Dirzo, R. (2017) Biological annihilation via the ongoing sixth mass extinction signaled by vertebrate population losses and declines. Proceedings of the National Academy of Sciences of the United States of America. DOI: https://doi.org/10.1073/pnas.1704949114 Ceballos, G., Dirzo, R., Young, H., Gelatti, M., Isaac, N. y Collen, B. (2014). Defaunation in the Anthropocene. Science 345 (6195), pp. 401-406. DOI: 10.1126/science.1251817

Clausewitz, K. (2004). De la guerra. Buenos Aires, Argentina: AGEBE.

Comité Invisible (2015). A nuestros amigos. Trad. Barbarroja, V. Logroño, España: Pepitas de calabaza editores.

Congreso de Estados Unidos (26 de octubre de 2001). DNA identification of terrorist and other violent offenders (Título V, sección 503), US Patriot Act of 2001. Recuperado de: https://www. congress.gov/107/plaws/publ56/PLAW-107publ56.pdf

Corominas, J. (1961). Breve diccionario etimológico de la lengua castellana. Madrid, España: Editorial Gredos.

Cortés, J. (2010). La ciudad cautiva. Control y vigilancia en el espacio urbano. Madrid: Ediciones Akal. Darraj, E; McElyeam B. (2017). "Precision Medicine, Privacy \& Cibersecurity", informe elaborado por para Northrop Grumman. En línea: http://health21initiative.org/article/precision-medicine-privacy-cybersecurity/ (revisado el 12/4/2020).

Feyerabend, P. (2002). Contra el Método. Trad. Hernán, F. Barcelona, España: Ediciones Folio. García, N. (2003). Libertad vigilada. El espionaje de las comunicaciones. Barcelona, España: Ediciones B. George, S. (2003). Informe Lugano: Cómo preservar el capitalismo en el siglo XXI. 9a ed. Trad. Wang, B. Barcelona, España: Icaria Editorial / Intermón.

González, S. (2014). Campo de guerra. Barcelona, España: Anagrama.

Goodman, A. (2007). Entrevista al general Wesley Clark, en Democracy Now!, el 2 de marzo de 2007. En línea: https://www.youtube.com/watch?v=bSL3JqorkdU o ver también: https:// www.democracynow.org/2007/3/2/gen_wesley_clark_weighs_presidential_bid (/revisado el $16 / 4 / 2020$ )

Hallsworth, S; Lea, J. (2011). Reconstructing Leviathan: Emerging contours of the security state. En Theoretical Criminology vol. 15 (2). Pp. 141-157.

IBM (2017). "adéntrese a la era cognitiva con Watson for Cyber Security", vídeo promocional de 2017. En línea: https://www.youtube.com/watch?v=za802DkILLI (revisado el 12/4/2020). (2016). Seguridad Cognitiva. Desarrolle sus defensas con la seguridad que comprende, razona y aprende. En línea: https://bit.ly/2wAbi8t (revisado el 12/4/2020).

IT User (2016). "El IBM Security Summit 2016 pone foco en la seguridad cognitiva”, publicado en IT User Tech \& Business, el 21 de setiembre de 2016. En línea: https://www.ituser.es/seguridad/2016/09/el-ibm-security-summit-2016-pone-foco-en-la-seguridad-cognitiva (revisado el $12 / 4 / 2020)$. 
Jakobs, G; Polaino-Orts, M. (2009) Terrorismo y Estado de derecho. Bogotá, Colombia: Universidad Externado de Colombia.

Larousse (2007). Diccionario Compact Español-Inglés/Inglés-Español. Barcelona, España: Larousse Editorial.

Leakey, R. y Lewin, R. (1997). La sexta extinción. El futuro de la vida y de la humanidad. Trad. Moya, A. Barcelona, España: Tusquets Editores.

Mattelart, A. (2009). Un mundo vigilado. Trad. Multigner, G. Barcelona, España: Ediciones Paidós Ibérica. Mecklin, John (Editor. 2017). It is two and a half minutes to midnight. 2017 Doomsday Clock Statement. Science and Security Board, Bulletin of Atomic Scientists. En: https://thebulletin. org/sites/default/files/Final_2017_Clock_Statement.pdf (revisado el 16/4/2020).

Merriam-Webster (s/f). "Gap", en Merriam-Webster Dictionary. En línea: https://www.merriamwebster.com/dictionary/gap (revisado el 18/4/2020).

$\operatorname{NOAA}(s / f)$. What is the biggest source of pollution in the ocean? En línea: https://oceanservice. noaa.gov/facts/pollution.html (revisado el 16/4/2020).

Ochoa, R. (2009). Muerte al Leviatán. Principios para una política desde la gente. México DF.: Editorial Jus.

Pais, A. (2017). "Qué es la era de la "aniquilación biológica" y por qué el culpable de la sexta extinción masiva en la Tierra no será un meteorito", publicado en BBC Mundo, el 19 de julio de 2017. En línea: https://www.bbc.com/mundo/noticias-40603476 (revisado el 21/12/2020)

PNAC (2000) Rebuilding America's defense. Strategy, forces and resources for a new century. Washington, Estados Unidos: PNAC. Disponible en: https://archive.org/details/RebuildingAmericasDefenses/mode/2up (revisado el 16/4/2020)

Schmitt, C. (2009) El concepto de lo político. Trad. Agapito, R. Madrid: Alianza Editorial.

Schmitt, C. (2008). El Leviatán en la doctrina del Estado de Thomas Hobbes. Coyoacán, México: Distribuciones Fontamara.

(2007) Tierra y Mar. Una reflexión sobre la historia universal. Trad. Fernández-Quintanilla, R. Madrid: Editorial Trotta

Stanley, J. (2011). "The war on Drugs and the Surveillance Society", publicado en el sitio web de la ACLU, el 6 de junio de 2011. En línea: https://www.aclu.org/blog/smart-justice/sentencingreform/war-drugs-and-surveillance-society (revisado el 12/4/2020)

Van der Ploeg, I. (2007). Genetics, biometrics and the informatization of the body. Ann Ist Super Sanita 43 (1), pp. 44-50. PMID: 17536153.

Vervaele, J. (2007). La legislación antiterrorista en Estados Unidos: ¿Inter arma silent leges? Ciudad Autónoma de Buenos Aires, Argentina: Editores del Puerto

Villagra, N. (2013). "Argos: epónimo o monstruo en Argos, héroe civilizador en Arcadia". En Repositório da Universidade de Lisboa, 23 de setiembre de 2013. En línea: http://hdl.handle. net/10451/29979 (revisado el 10/4/2020).

Weisse, M; Goldman, L. (2017). "La pérdida de cobertura arbórea mundial ascendió al 51\% en 2016", publicado en Global Forest Watch, el 24 de octubre de 2017. En línea: https://blog.globalforestwatch.org/data-and-research/la-perdida-de-cobertura-boscosa-mundial-ascendio-al51-en-2016 (revisado el 16/4/2020).

Whitaker, R. (1999). El fin de la privacidad. Cómo la vigilancia total se está convirtiendo en realidad. Trad. Prat, L. Barcelona, España: Paidós.

World Wide Fund for Nature (2018). Informe Planeta Vivo 2018: Apuntando más alto. Trad. Walter, A. Gland, Suiza. En: http://awsassets.wwf.es/downloads/informe_planeta_vivo_2018.pdf (revisado el 18/4/2020).

Zaffaroni, E. (2006) El Enemigo en el Derecho penal. Buenos Aires: Ediar 